\title{
Glia-dependent TGF- $\beta$ signaling, acting independently of the TH17 pathway, is critical for initiation of murine autoimmune encephalomyelitis
}

\author{
Jian Luo, ${ }^{1}$ Peggy P. Ho, ${ }^{1}$ Marion S. Buckwalter, ${ }^{1}$ Tiffany Hsu, ${ }^{1}$ Lowen Y. Lee, ${ }^{1}$ Hui Zhang, ${ }^{1}$ \\ Dae-Kee Kim, ${ }^{2}$ Seong-Jin Kim, ${ }^{3}$ Sanjiv S. Gambhir, ${ }^{4}$ Lawrence Steinman, ${ }^{1}$ and Tony Wyss-Coray ${ }^{1,5}$

\begin{abstract}
${ }^{1}$ Department of Neurology and Neurological Sciences, Stanford University School of Medicine, Stanford, California, USA. ${ }^{2}$ College of Pharmacy, Ewha Womans University, Seodaemun-gu, Seoul, Republic of Korea. ${ }^{3}$ Laboratory of Cell Regulation and Carcinogenesis, National Cancer Institute, National Institutes of Health, Bethesda, Maryland, USA. ${ }^{4}$ Molecular Imaging Program at Stanford (MIPS) and Bio-X Program, Department of Radiology, Stanford University School of Medicine, Stanford, California, USA. ${ }^{5}$ Geriatric Research Education and Clinical Center,
\end{abstract} VA Palo Alto Health Care System, Palo Alto, California, USA.

\begin{abstract}
Autoimmune encephalomyelitis, a mouse model for multiple sclerosis, is characterized by the activation of immune cells, demyelination of axons in the CNS, and paralysis. We found that TGF- $\beta 1$ synthesis in glial cells and TGF- $\beta$-induced signaling in the CNS were activated several days before the onset of paralysis in mice with autoimmune encephalomyelitis. While early production of TGF- $\beta 1$ was observed in glial cells TGF- $\beta$ signaling was activated in neurons and later in infiltrating $T$ cells in inflammatory lesions. Systemic treatment with a pharmacological inhibitor of TGF- $\beta$ signaling ameliorated the paralytic disease and reduced the accumulation of pathogenic T cells and expression of IL- 6 in the CNS. Priming of peripheral T cells was not altered, nor was the generation of TH17 cells, indicating that this effect was directed within the brain, yet affected the immune system. These results suggest that early production of TGF- $\beta 1$ in the CNS creates a permissive and dangerous environment for the initiation of autoimmune inflammation, providing a rare example of the brain modulating the immune system. Importantly, inhibition of TGF- $\beta$ signaling may have benefits in the treatment of the acute phase of autoimmune CNS inflammation.
\end{abstract}

\section{Introduction}

MS is an inflammatory demyelinating disease of the CNS. It is characterized by myelin destruction and axonal loss leading to progressive disability $(1,2)$. EAE is the prototypical animal model for MS and can be induced in susceptible rodents by immunization with myelin antigens such as myelin oligodendrocyte glycoprotein (MOG) or by adoptive transfer of myelin-specific Th1 $\mathrm{CD} 4^{+} \mathrm{T}$ cells $(3,4)$. As a result, inflammatory cells consisting mostly of $\mathrm{CD} 4^{+}$ $\mathrm{T}$ cells, monocytes, and macrophages infiltrate the CNS, leading to demyelination and neuronal damage $(3,4)$. While a great deal is known about the development of autoimmune $\mathrm{T}$ cells in the periphery from experimental animal models, it is still unclear how these autoreactive $\mathrm{T}$ cells take residence in the CNS, a milieu classically considered as "out of bounds" or "immune privileged," and how they then exert their destructive properties.

TGF- $\beta$ s are members of a superfamily of multifunctional cytokines with key functions in development, patterning, carcinogenesis, fibrosis, and immune responses $(5,6)$. In the immune system, TGF- $\beta 1$ is involved in the induction of immune tolerance by regulating $T$ cell proliferation, differentiation, and survival $(7,8)$. In addition, TGF- $\beta 1$ regulates the initiation and resolution of inflam-

Nonstandard abbreviations used: ALK5, activin-like kinase receptor 5; dpi, day(s) post immunization; GFAP, glial fibrillary acidic protein; MOG, myelin oligodendrocyte glycoprotein; PT, pertussis toxin; RFP, red fluorescent protein; SBE, smad-binding element(s).

Conflict of interest: The authors have declared that no conflict of interest exists. Citation for this article: J. Clin. Invest. 117:3306-3315 (2007). doi:10.1172/JCI31763. matory responses through its effects on chemotaxis, activation, and survival of immune cells $(7,8)$. Among the 3 TGF- $\beta$ isoforms (TGF- $\beta 1,-\beta 2$, and $-\beta 3$ ), TGF- $\beta 1$ is the predominant isoform expressed in the immune system (9). In the CNS, TGF- $\beta 1$ helps orchestrate the response to brain injury and has been implicated in a number of disorders, including stroke, Parkinson disease, and Alzheimer disease (10). TGF- $\beta 1$ and its receptors are expressed in the CNS inflammatory lesions of MS patients and in various animal models of the disease (11-13), suggesting a role in the disease process. However, their role in EAE seems paradoxical. Systemic administration of exogenous TGF- $\beta 1$ in mice prevents or inhibits EAE $(13,14)$, and administration of TGF- $\beta$-neutralizing antibodies enhances disease severity (15), suggesting a protective role of TGF- $\beta 1$ in EAE. In contrast, overproduction of TGF- $\beta 1$ locally in the brain results in more severe EAE, with earlier disease onset and larger mononuclear cell infiltrates in the CNS (16). This discrepancy between the roles of TGF- $\beta$ suggests that they may have autonomous functions. Little consideration has been given to possible unidirectional influences of the brain on the immune system.

The recent identification of TGF- $\beta 1$ as a crucial factor for the differentiation of TH17 (17-19), an IL-17-producing T cell subset believed to be autoreactive and disease promoting (20), further supports a pathogenic role of TGF- $\beta 1$ in EAE (21). While these recent studies highlight the critical role of TGF- $\beta 1$ in the pathogenesis of EAE and MS in the priming and expansion of autoreactive $T$ cells, they do not approach the important question of how TGF- $\beta 1$, produced in the CNS, modulates the disease process. We report here that TGF- $\beta 1$ plays a role that temporally occurs first 

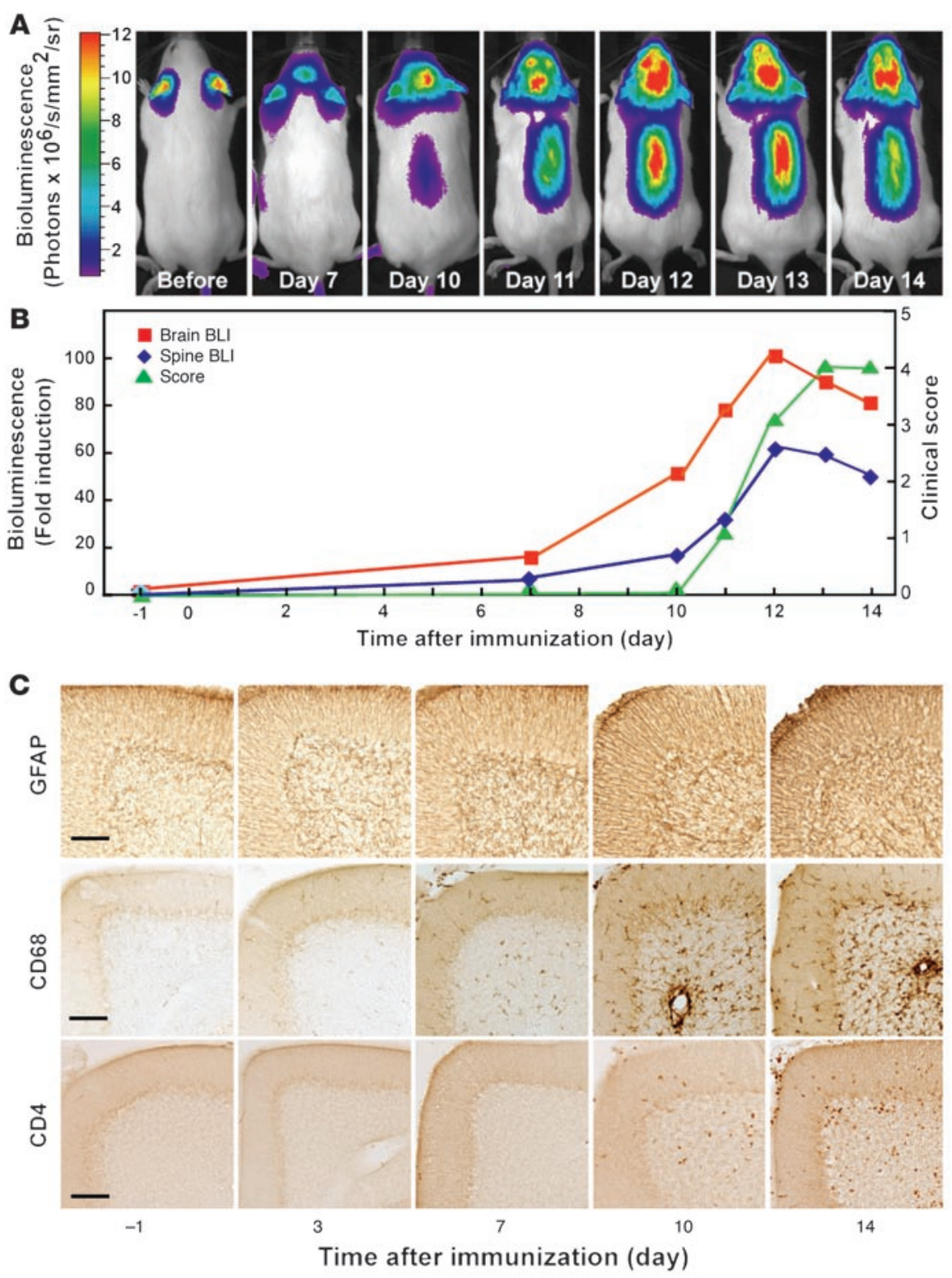

\section{Figure 1}

Astrogliosis and neuroinflammation precede clinical signs in EAE. (A and B) EAE was induced in GFAP-luc mice with $\mathrm{MOG}_{35-55}$ emulsified in CFA plus PT, and bioluminescence was recorded in living mice $(n=7)$ injected with luciferin $(150 \mathrm{mg} / \mathrm{kg}) 1$ day before $(-1)$ and at $3,7,10$, or 14 dpi. Time course of bioluminescence recorded in a representative mouse $(\mathbf{A})$ and the bioluminescence expressed as fold induction plotted with clinical score (B). (C) Mice were sacrificed at indicated time points. Sagittal brain sections from control $(-1)$ or EAE mice sacrificed at different time points were examined for neuroinflammation, and images were taken from cerebellum. Neuroinflammation was assessed by immunohistochemistry as a function of astrogliosis (GFAP), microgliosis (CD68), and T lymphocyte infiltration (CD4). Scale bars: $100 \mu \mathrm{m}$. in the inflammatory process in the CNS and is distinct from its role outside the brain on $\mathrm{T}$ cells of the immune system. This is an example of the brain signaling the immune system, a rare situation with at least some precedents (22-24). Examples of bidirectional interactions between brain and the immune system occur in the febrile response while examples of the immune system influencing the brain are at the heart of our understanding of autoimmune diseases such as $\operatorname{EAE}(23,25)$.

\section{Results}

Astrogliosis and neuroinflammation precede clinical signs in EAE. To understand the early events in the pathogenesis of autoimmune disease in the brain, we studied the activation of astrocytes during EAE in a transgenic reporter mouse in vivo (26). Astrocytes are rapidly activated at sites of inflammation, as demonstrated by increased expression of glial fibrillary acidic protein (GFAP) $(27,28)$. Astrocyte activation can be monitored noninvasively in vivo using bioluminescence imaging in mice expressing luciferase under the control of a GFAP promoter (26). Induction of EAE in these mice by immunization with $\mathrm{MOG}_{35-55}$ peptide and adjuvants led to a small but detectable increase in bioluminescence in the brain as early as 3 days post immunization (dpi) (data not shown) and to a consistently significant increase at $7 \mathrm{dpi}$ (Figure 1A). Importantly, mice did not show any clinical signs of disease until $11 \mathrm{dpi}$ (Figure 1B), consistent with astrocyte activation preceding clinical manifestations by several days $(27,28)$. Similar results were also obtained in the spinal cord (Figure 1, A and B).

In agreement with these imaging observations, immunohistochemical analysis of brain sections from mice sacrificed at various time points after immunization showed early activation of astrocytes (GFAP) and microglia (CD68) several days before clinical onset of disease (Figure 1C). Glial activation (gliosis) was detected as early as $3 \mathrm{dpi}$ in the cerebellum and was less prominent in brain stem and spinal cord (data not shown). Interestingly, significant $\mathrm{T}$ cell infiltrates were not seen until $10 \mathrm{dpi}$, just before clinical symptoms were noticeable (Figure 1C). Thus, local CNS 

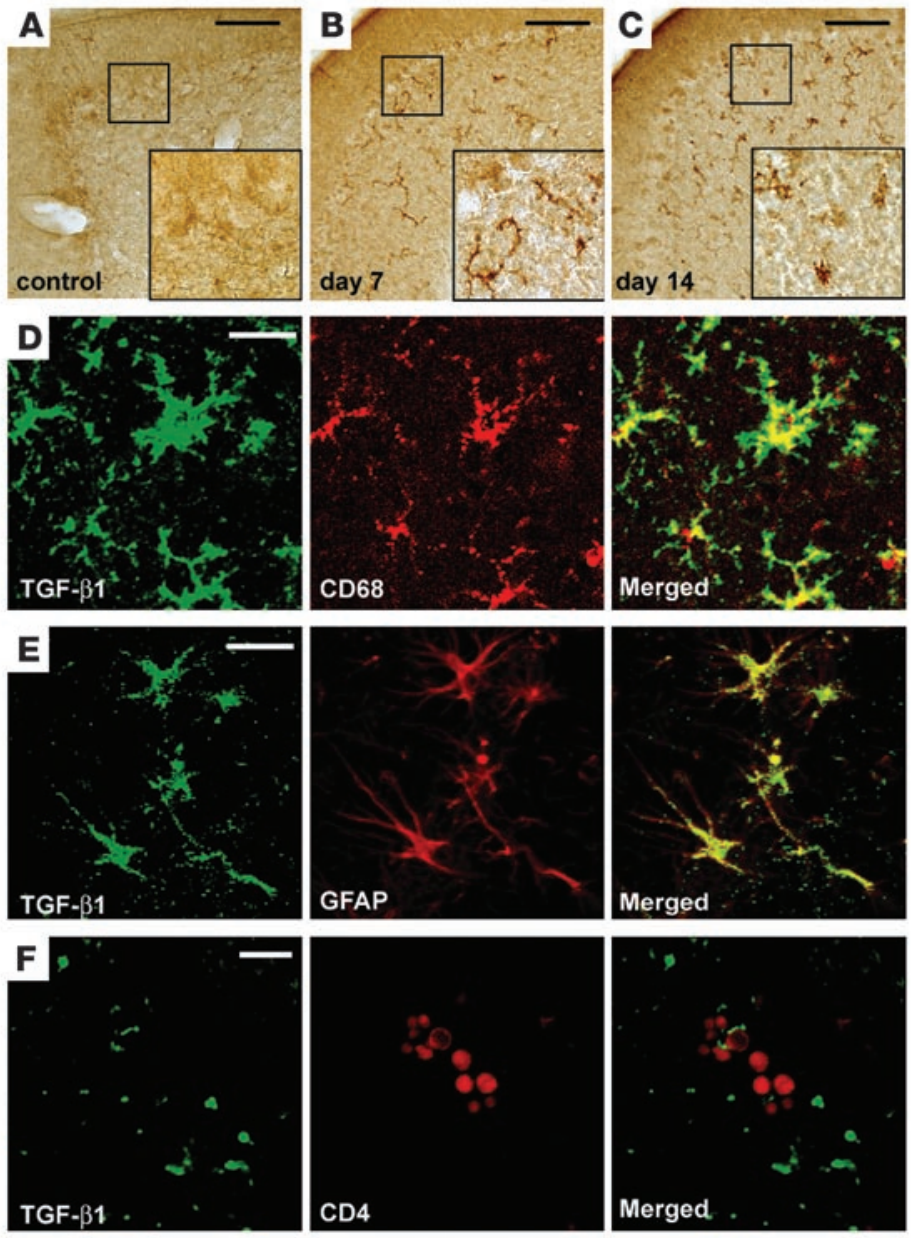

\section{Figure 2}

Double immunolabeling and confocal microscopy shows TGF- $\beta 1$ expression in glial cells but not infiltrating lymphocytes. GFAPluc mice were immunized with $\mathrm{MOG}_{35-55}$ and adjuvants (B-F) or injected with PBS as control (A). (A-C) Sagittal brain sections from control $(\mathbf{A})$ or EAE mice sacrificed at 7 (B) or $14(\mathbf{C})$ dpi were immunostained for TGF- $\beta 1$, and images were taken from cerebellum. Inserts show boxed regions at higher magnification. (D-F) Confocal microscope images from brain sections of an EAE mouse sacrificed at $7 \mathrm{dpi}$ and double immunolabeled with antibodies against TGF- $\beta 1$ (green) and cell type-specific markers CD68 (microglia, D), GFAP (astrocytes, E), and CD4 (T cell subset, F) (red). TGF- $\beta 1$-expressing cells appear yellow after superimposition. Scale bars: $100 \mu \mathrm{m}$ (A-C); $20 \mu \mathrm{m}$ (D-F).

bioluminescence emitting first from the brain and later from the spinal cord, indicating early activation of TGF- $\beta$ signaling (Figure 3A). Consistent with GFAP-luc mice, this signal appeared at least 4 days before clinical signs were apparent (Figure 3A), indicating a role of TGF- $\beta$ signaling in the earliest phase of EAE. Bioluminescence measurements were confirmed by tissue luciferase activity assay in both brain and spinal cord (Supplemental Figure 1; supplemental material available online with this article; doi:10.1172/JCI31763DS1).

To identify the cellular source of the bioluminescence signal and because no specific antibodies are available to detect luciferase expression in brain tissue $(31,32)$, we generated new reporter mice for the TGF- $\beta$ signaling pathway. These SBE-lucRT mice express a trifusion protein containing luciferase, red fluorescent protein (RFP), and thymidine kinase (33) under the control of the same SBE promoter as the original SBE-luc reporter mice $(31,32)$. In agreement with SBEluc mice (32), baseline TGF- $\beta$ signaling in SBE-lucRT mice was detected in large pyramidal neurons in the hippocampus and cortex (data not shown) and Purkinje cells of the cerebelresponses precede significant $\mathrm{T}$ cell infiltration and clinical disease onset, underlining the importance of the local CNS environment in the development of the disease.

Early upregulation of TGF- $\beta 1$ and activation of TGF- $\beta$ signaling in the CNS. TGF- $\beta 1$ is an important injury-response factor and modulator of immune responses (7) and is produced locally in the brain during MS and EAE (11-13). Indeed, strong TGF- $\beta 1$ immunoreactivity was observed in the $\mathrm{CNS}$ of mice immunized with $\mathrm{MOG}_{35-55}$ peptide as early as $7 \mathrm{dpi}$ (Figure 2, B and C), consistent with the early timing of activation of glial cells. TGF- $\beta 1$ immunoreactivity was present at 7 and $14 \mathrm{dpi}$ in cerebellum (Figure 2), cortex, brain stem, and spinal cord (data not shown), which are brain regions highly susceptible to $\mathrm{T}$ cell infiltration and demyelination. Double immunolabeling and confocal microscopy identified microglia (Figure 2D) and astrocytes (Figure 2E) as the main TGF- $\beta 1$-producing cells, consistent with previous reports in acute brain injury $(29,30)$. CD $4^{+} \mathrm{T}$ cells showed no significant TGF- $\beta 1$ immunoreactivity at 7 (Figure $2 \mathrm{~F}$ ) or $14 \mathrm{dpi}$ (not shown).

To determine whether increased TGF- $\beta 1$ production leads to activation of TGF- $\beta$ signaling, we used SBE-luc (SBE, smad-binding element) mice, which harbor a TGF- $\beta$-responsive luciferase reporter gene and have been shown to reliably indicate activation of TGF- $\beta$ signaling $(31,32)$. Thus, TGF- $\beta$ signaling in these animals can be monitored in vivo over time by bioluminescence imaging. Immunization of SBE-luc mice with $\mathrm{MOG}_{35-55}$ peptide resulted in lum (Figure 3B). Immunization with $\mathrm{MOG}_{35-55}$ led to infiltration of $\mathrm{T}$ cells and increased RFP immunoreactivity starting at $7 \mathrm{dpi}$ in neurons (Figure 3, C and D), consistent with bioluminescence imaging. Importantly, infiltrated $\mathrm{CD} 4^{+} \mathrm{T}$ cells were RFP immunoreactive as well (Figure 3, E and H), indicating that TGF- $\beta$ signaling is activated in these cells. Microglia (Figure 3F) and astrocytes (Figure 3G) showed no significant RFP immunoreactivity. Similar results were obtained from immunostaining of phosphorylated Smad2 (32), a primary downstream target of the TGF- $\beta$ signaling pathway (data not shown). These results demonstrate that TGF- $\beta$ signaling is activated early after MOG $_{35-55}$ immunization and increases with disease progression and that neurons and later $\mathrm{CD} 4^{+} \mathrm{T}$ cells are the main targets of TGF- $\beta$ signaling in the brain at this stage of the disease.

Induction of EAE requires antigen $\left(\mathrm{MOG}_{35-55}\right)$ to be emulsified in CFA, an immune stimulant that recruits innate immune responses in the periphery and possibly in the CNS (3). In addition, pertussis toxin (PT) is administered to open the blood-brain barrier and provide entry of $T$ cells and macrophages into the CNS (34). To determine whether adjuvant or $\mathrm{MOG}_{35-55}$ peptide might cause the early increase in TGF- $\beta 1$ production or the activation of TGF- $\beta$ signaling, we injected SBE-lucRT mice with CFA alone, PT alone, or combinations thereof with $\mathrm{MOG}_{35-55}$ and analyzed their brains. Mice receiving CFA alone, but not those receiving PT alone, showed a significant increase in TGF- $\beta 1$ immunoreactiv- 

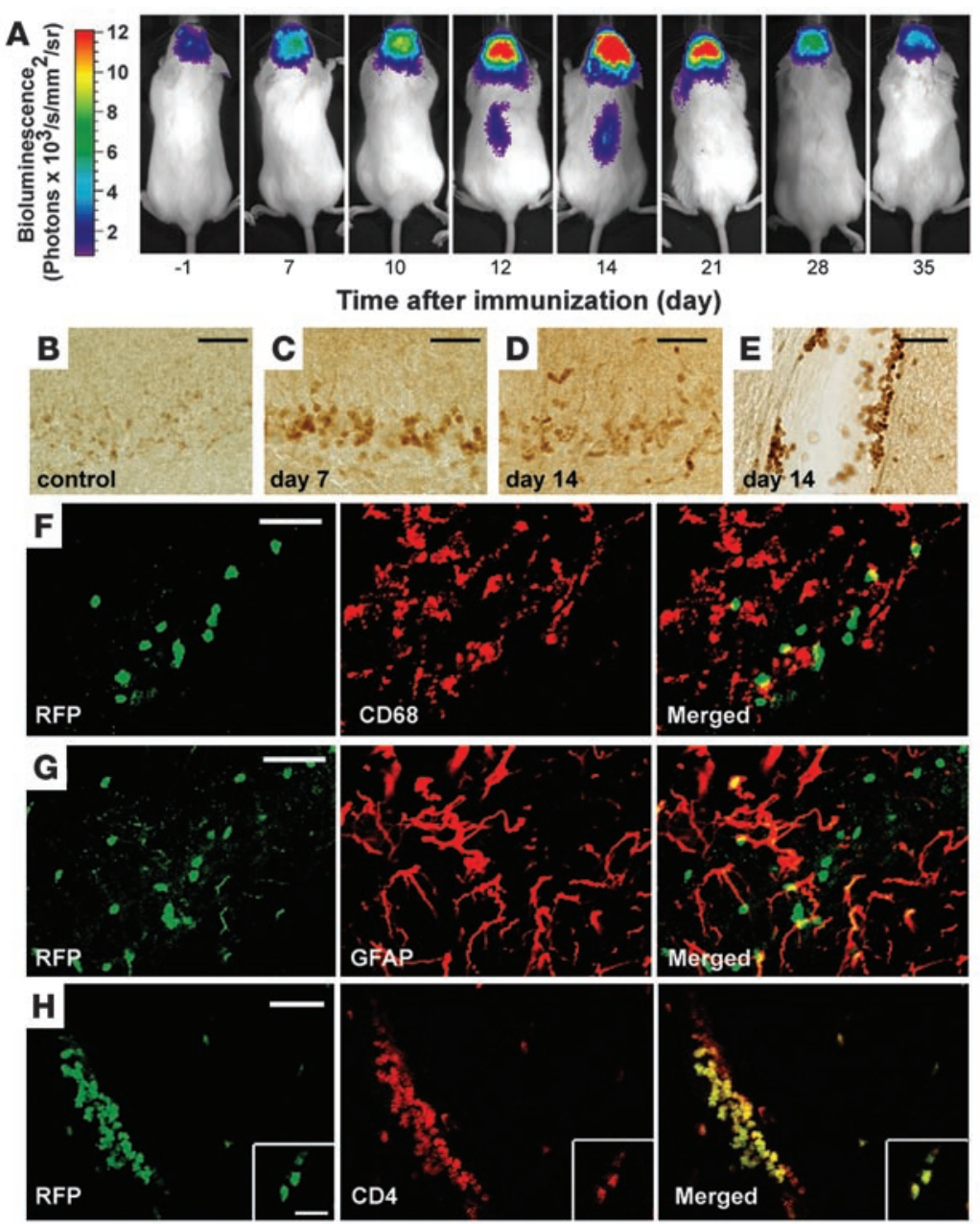

\section{Figure 3}

Early activation of TGF- $\beta$ signaling in brains of SBE-luc (A) or SBE-lucRT (B-H) mice after immunization. (A) Time course showing bioluminescence signals indicative of TGF- $\beta$ signaling in a representative SBE-luc mouse. (B-H) Activation of TGF- $\beta$ signaling indicated by reporter gene expression in neurons and infiltrating lymphocytes. SBE-lucRT mice were immunized with $\mathrm{MOG}_{35-55}$ and adjuvants (C-E) or injected with PBS as control (B). (B-E) Sagittal brain sections were stained for RFP, and images were taken from the cerebellum granule cell layer. $(\mathbf{F}-\mathbf{H})$ Confocal microscope images of double immunolabeling with antibodies against RFP (green) and cell type-specific markers (red): CD68 (microglia, F), GFAP (astrocyte, G), and CD4 (T cell subset, H). RFP-expressing cells appear yellow after superimposition. Sections were from a mouse sacrificed at $14 \mathrm{dpi}(\mathbf{D}-\mathbf{E})$. Scale bars: $50 \mu \mathrm{m}(\mathbf{A}-\mathbf{E}) ; 20 \mu \mathrm{m}(\mathbf{F}-\mathbf{H})$. Insets in $\mathbf{H}$ show RFP-expressing $\mathrm{CD}^{+} \mathrm{T}$ cells in cerebellum parenchyma. Scale bar: $20 \mu \mathrm{m}$.

Astrocyte-targeted overexpression of TGF- $\beta 1$ results in earlier onset of EAE. These results raise the question of whether the early activation of TGF- $\beta$ signaling delays or promotes disease. In support of a proinflammatory role for TGF- $\beta 1$ in EAE, transgenic mice overproducing TGF- $\beta 1$ in astrocytes (GFAPpTGF- $\beta 1$ ) (36) showed earlier disease onset and more severe disease when immunized with spinal cord homogenate in CFA (16). In concordance with these results, we show here that the same TGF- $\beta 1$ transgenic mice backcrossed onto a C57BL/ 6 genetic background and immunized with $\mathrm{MOG}_{35-55}$ in $\mathrm{CFA}$ also had significantly earlier disease onset and more severe disease than littermate controls (Supplemental Table 1$)$. Thus, TGF- $\beta 1$ produced locally in

ity in the CNS, similar to mice receiving the full immunization cocktail (MOG $_{35-55}$ emulsified in CFA plus PT; Supplemental Figure 2). Combining $\mathrm{MOG}_{35-55}$ or PT with CFA did not further increase TGF- $\beta 1$ immunoreactivity. Similar results were obtained from biochemical measurements of tissue luciferase activity (data not shown), demonstrating that CFA alone can activate TGF- $\beta$ signaling in the CNS. Early studies showed that CFA preimmunization protects against subsequent EAE induction (35). It would be interesting to investigate whether this protection is due to increased TGF- $\beta 1$. the brain exacerbated EAE. To determine whether this effect of TGF- $\beta 1$ is due to altered priming of encephalitogenic T cell responses, we isolated $\mathrm{T}$ cells from the spleen and tested their in vitro recall responses to secondary exposure to $\mathrm{MOG}_{35-55}$. T cells derived from TGF- $\beta 1$ transgenic mice showed no significant difference in recall responses to $\mathrm{MOG}_{35-55}$ compared with those of nontransgenic mice (Supplemental Figure 3). In addition, astrocyte-derived TGF- $\beta 1$ in these mice did not significantly change the production of IL-6, IL-12, IL-17, and IL-23 in cultured splenocytes (Supplemental Figure 3).

Table 1

Pharmacological inhibition of TGF- $\beta$ signaling ameliorates EAE

$\begin{array}{lcccccc}\text { Group } & \begin{array}{c}\text { Day of onset } \\ \text { (range) }\end{array} & \begin{array}{c}\text { Peak clinical } \\ \text { (spinal cord) }\end{array} & \begin{array}{c}\text { Peak body weight loss } \\ \text { (\% of preinjury) }\end{array} & \begin{array}{c}\text { Peak brain BLI } \\ \text { (fold induction) }\end{array} & \begin{array}{c}\text { Peak spinal cord BLI } \\ \text { (fold induction) }\end{array} & \begin{array}{c}\text { T cell infiltration } \\ \text { (spinal cord) }\end{array} \\ \text { SBE-luc mice } & & & & & & \\ \text { EAE + PBS } & 9.3 \pm 0.2(9-11) & 3.42 \pm 0.5(\mathrm{~d} 14) & 86.4 \pm 0.04 & 9.8 \pm 2.5 & 5.7 \pm 0.5 & 127.88 \pm 26.87 \\ \text { EAE + IN-1130 } & 13.2 \pm 0.1(13-14)^{\mathrm{A}} & 1.33 \pm 0.5^{\mathrm{A}} & 94.9 \pm 0.04 & 4.8 \pm 1.4^{\mathrm{B}} & 3.8 \pm 0.4^{\mathrm{B}} & 4.67 \pm 1.67^{\mathrm{A}}(\mathrm{d} 11) \\ \text { GFAP-luc mice } & & & & & & \\ \text { EAE + PBS } & 10.5 \pm 0.3(10-11) & 4.25 \pm 0.3 & 81.4 \pm 0.02 & 95.0 \pm 15.5 & 57.5 \pm 14.1 & 466.80 \pm 47.90 \\ \text { EAE + IN-1130 } & 11.3 \pm 0.8(10-13) & 2.75 \pm 0.9 & 91.9 \pm 0.04^{\mathrm{B}} & 28.3 \pm 7.5^{\mathrm{A}} & 25.3 \pm 12.1^{\mathrm{B}} & 230.6 \pm 42.28^{\mathrm{B}}(\mathrm{d} 14) \\ \end{array}$

Inhibition of TGF- $\beta$ signaling by IN-1130 ameliorates EAE. Data are expressed as mean \pm SEM. ${ }^{A} P<0.01,{ }^{B} P<0.05$ compared with EAE + PBS by unpaired Student's $t$ test. BLI, bioluminescence imaging signals. 

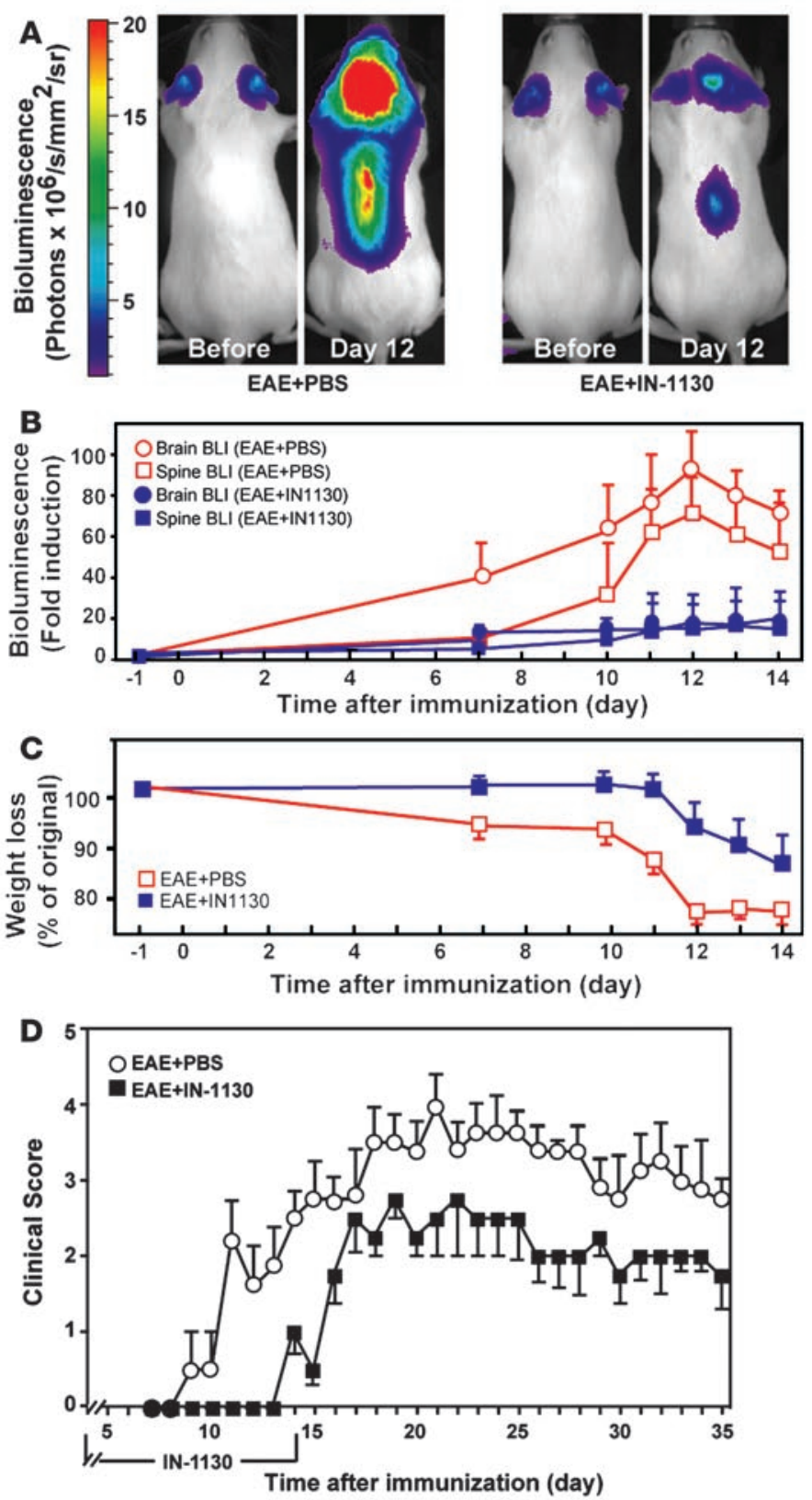

Inbibiting TGF- $\beta$ signaling ameliorates autoimmune encephalomyelitis. To determine whether TGF- $\beta$ signaling is necessary for the development of EAE, we inhibited TGF- $\beta$ signaling by treating mice with IN-1130, an inhibitor of activin-like kinase receptor 5 (ALK5, TGF- $\beta$ type I receptor) (37). As a competitive inhibitor of the ATP-binding site of ALK5, IN-1130 blocks TGF- $\beta$-mediated ALK5-dependent signaling (37). Treatment with IN-1130 significantly inhibited TGF- $\beta$ signaling and astrogliosis in SBE-luc and GFAP-luc mice after $\mathrm{MOG}_{35-55}$ immunization (Figure 4, A and B, Table 1, and Supplemental Figure 4). More importantly, disease severity was reduced and disease onset was delayed (Figure 4D and Table 1 ), demonstrating that IN-1130 reduces not only TGF- $\beta$ signaling in the CNS but also the onset and severity of paralytic disease. Moreover, IN-1130 treatment resulted in a significant reduction of weight loss in GFAP-luc mice with EAE (Figure 4C and

\section{Figure 4}

Pharmacological inhibition of TGF- $\beta$ signaling ameliorates EAE. GFAP-luc mice (A-C, $n=4-7$ per group) or SBE-luc mice (D, $n=10-12$ per group) were immunized with $\mathrm{MOG}_{35-55}$ emulsified in CFA and treated with the TGF- $\beta$ receptor kinase inhibitor IN-1130 (closed symbols) or PBS (open symbols) from 1-14 (A-C) or 3-14 (D) dpi. Daily bioluminescence and clinical assessment (weight loss, C; clinical score, D) were recorded in a blinded manner. Bioluminescence is shown from representative mice of each group individually (A) or as mean \pm SEM (B). Similar results were obtained in 2 independent experiments. Data are shown as mean \pm SEM.

Table 1). Similar to TGF- $\beta 1$ transgenic mice, IN-1130-treated mice showed no significant changes in peripheral $\mathrm{T}$ cell priming (Supplemental Figure 5).

Inhibition of TGF- $\beta$ signaling leads to reduced $T$ cell infiltration and TGF- $\beta 1$ expression in the CNS. Given the observation that MOG $_{35-55}$-immunized mice treated with IN-1130 had no overt changes in their peripheral immune response, we tested to determine whether IN-1130 affects the accumulation of pathogenic/effector cells in the CNS. Indeed, treatment with IN-1130 dramatically reduced the number of $\mathrm{CD}^{+} \mathrm{T}$ cells in the spinal cord at $11 \mathrm{dpi}$ (SBE-luc mice) (Figure 5, A and B) and $14 \mathrm{dpi}$ (GFAP-luc mice) (Figure 5C and Table 1). To further confirm the inhibition of TGF- $\beta$ signaling by IN-1130, we used quantitative real-time PCR analysis to determine the expression of TGF- $\beta 1$. TGF- $\beta 1$ was upregulated in the CNS at $14 \mathrm{dpi}$, but its induction was significantly reduced in IN-1130-treated mice (Figure 5D). TGF- $\beta 1$ can induce its own synthesis (38), and previous findings showed that IN-1130 treatment reduced TGF- $\beta 1$ gene expression in an animal model of kidney fibrosis (37). Moreover, IN-1130 treatment almost completely inhibited the upregulation of IL- 6 in the CNS (Figure 5E), a proinflammatory cytokine induced by TGF- $\beta 1$ and critical in the induction of a number of experimental autoimmune conditions including EAE (39). Interestingly, the expression of IL-23, a cytokine important in Th17 expansion (40), was not significantly affected by IN-1130 treatment (Figure 5F). In agreement with a limited role of IL-23 in the TGF- $\beta 1$-dependent effects reported here, treatment of EAE with anti-IL-23 antibodies in SBE-lucRT mice did not significantly reduce TGF- $\beta$ signaling despite its protective effect on the clinical progression of disease (Supplemental Figure 6). Together, our findings show that reduced TGF- $\beta$ signaling in the CNS results in the accumulation of fewer effector T cells and thus less CNS inflammation and disease.

Inbibition of TGF- $\beta$ signaling does not significantly change the percentage of $\mathrm{CD}^{+} \mathrm{T}$ cell subsets in brain or spleen. To determine whether reduced accumulation of effector $\mathrm{T}$ cells in the brains of IN-1130-treated mice is due to the reduction of a specific $\mathrm{T}$ cell subset, we isolated lymphocytes from spinal cords and spleens of mice at $20 \mathrm{dpi}$ and measured total $\mathrm{CD}^{+}$infiltration $\left(\mathrm{CD}^{+}\right.$cells) and $\mathrm{CD}^{+}{ }^{+} \mathrm{T}$ cell subsets based on expression of IL-4, IFN- $\gamma$, Foxp3, or IL-17. IN-1130 treatment did not change the overall number of $\mathrm{CD}^{+} \mathrm{T}$ cells in the spleen (Figure 6A) or the percentage of the various $\mathrm{T}$ cell subsets (Figure 6C), consistent with the finding that IN-1130 does not change the production of IL-6, IL-12, IL-17, and IL-23 in splenocytes (Supplemental Figure 5). In contrast, IN-1130 treatment strongly reduced the number of $\mathrm{CD}^{+} \mathrm{T}$ cells in the spinal cord (Figure 6A). Again, the percentage of $\mathrm{CD}^{+} \mathrm{T}$ cell subsets between the 2 groups was not statistically significant (Figure 6B). 

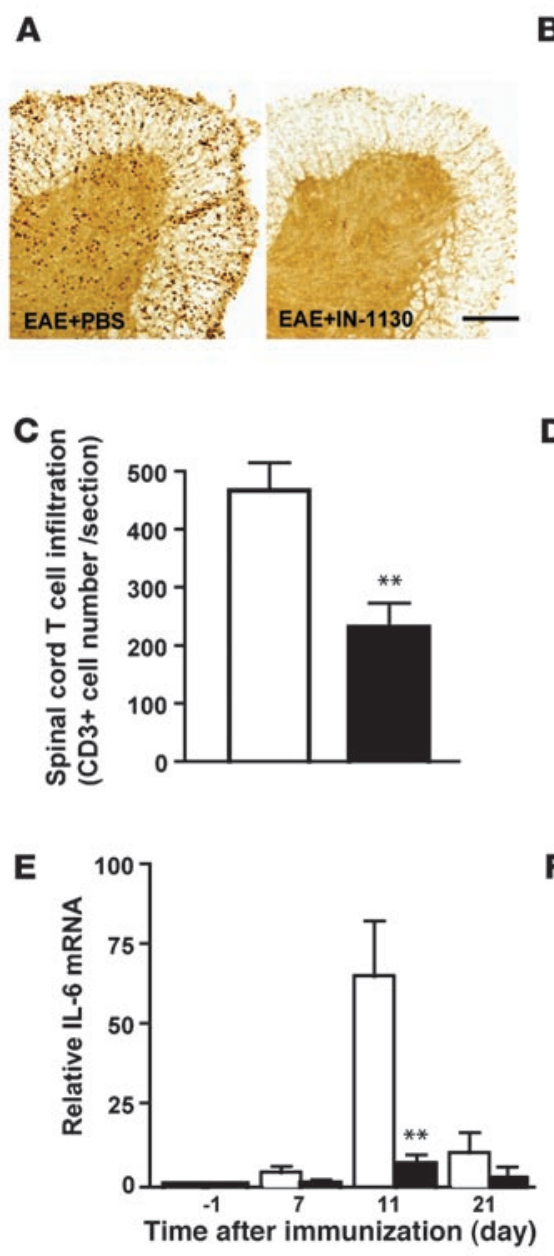
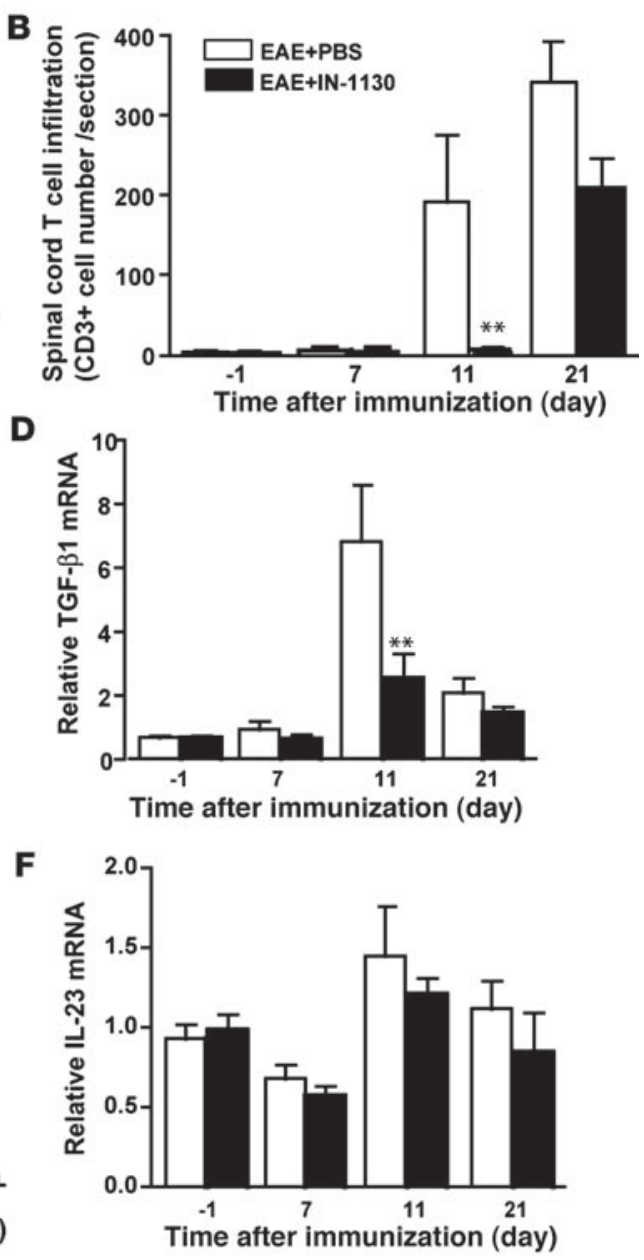

\section{Figure 5}

Inhibition of TGF- $\beta$ signaling leads to reduced $T$ cell accumulation and TGF- $\beta 1-d e p e n d e n t$ gene expression in the spinal cord. SBE-luc mice (A, B, D, E, and $\mathbf{F}, n=3-4$ per group) or GFAP-luc mice (C, $n=4-7$ per group) were immunized with $\mathrm{MOG}_{35-55}$ emulsified in CFA and treated with IN-1130 (black bars) or PBS (white bars). Mice were sacrificed at indicated time points (B, D, and $\mathbf{E})$ or at $14 \mathrm{dpi}$ (C). (A-C) Spinal cord cross sections ( $n=2-4$ per mouse) were stained with an antibody against CD3 to assess $T$ cell accumulation. (A) Representative images from spinal cord sections of SBE-luc mice sacrificed at $11 \mathrm{dpi}$. (D-F) Relative levels of TGF- $\beta 1$ (D), IL-6 (E), and IL-23 (F) expression in the spinal cords of SBE-luc mice measured by quantitative real-time PCR. Bars show mean \pm SEM. ${ }^{* *} P<0.01$ compared with EAE plus PBS. Scale bar: $100 \mu \mathrm{m}$.
To determine in which T cells TGF- $\beta$ signaling is activated in EAE, we immunized SBE-lucRT mice and measured the percentage of RFP-expressing (TGF- $\beta$ signaling activated) $\mathrm{CD} 4^{+} \mathrm{T}$ cell subsets in the spinal cord and spleen. Immunohistochemistry showed activated TGF- $\beta$ signaling in infiltrated T cells in the CNS (Figure 3 ), and foci of similar T cells were found in the spleen (Figure 7, A and $\mathrm{B}$ ). In mice with EAE, about $30 \%$ of $\mathrm{CD}^{+}$cells in the spleen and $50 \%$ of $\mathrm{CD}^{+}$cells in the spinal cord were RFP positive. Consistent with the bioluminescence imaging in SBE-luc mice, IN-1130 treatment led to significantly reduced RFP reporter gene expression in $\mathrm{CD}^{+} \mathrm{T}$ cells isolated from both spinal cord and spleen in SBE-lucRT mice (Figure 7C), indicating inhibition of TGF- $\beta$ signaling by IN-1130. However, the composition of the RFP ${ }^{+}$ $\mathrm{T}$ cells in IN-1130-treated mice was not significantly different from that in PBS-treated mice in both spinal cord (Figure 7, D and E) and spleen (Figure 7, D and F), further supporting that inhibiting TGF- $\beta$ signaling by IN-1130 does not exert T cell subset-specific effects. The analysis of $\mathrm{T}$ cell subsets shows that reduced CD4+ $\mathrm{T}$ cell accumulation in the brain after IN-1130 treatment is not due to a specific reduction of a major $\mathrm{T}$ cell subset.

\section{Discussion}

The present study demonstrates that the local environment in the CNS is critical in the initiation of autoimmune encephalitis. Using luciferase reporter mice and in vivo bioluminescence imaging, we discovered that astrocytes, microglia, and Smad-dependent TGF- $\beta$ signaling are activated early in the CNS, several days before clinical onset of disease. The adjuvant CFA is likely sufficient to initiate these early events, leading to increased production of TGF- $\beta 1$ in astrocytes and microglia. Consequently, TGF- $\beta$ signaling is activated in neurons and later in infiltrating T cells. The inhibition of TGF- $\beta$ signaling delayed and ameliorated progression of autoimmune encephalomyelitis by significantly reducing the accumulation of T cells in the CNS but not by altering the priming of peripheral autoreactive $\mathrm{T}$ cells or the expansion of specific $\mathrm{CD}^{+} \mathrm{T}$ cell subsets.

In autoimmune inflammatory disease, autoreactive $T$ cells typically generated in lymphoid organs not only need to infiltrate but also need to successfully accumulate in the target organ to cause disease. TGF- $\beta 1$ can participate in all these processes by regulating $\mathrm{T}$ cell proliferation, differentiation, and apoptosis as well as chemotaxis and homing $(7,8)$. These site-specific actions may explain the seemingly paradoxical effects of TGF- $\beta 1$ in inhibiting or promoting inflammatory responses and autoimmunity. Indeed in EAE, TGF- $\beta 1$ was initially discovered to be immunosuppressive and to inhibit disease $(13,14)$ but is now recognized as a critical factor in the genesis of autoreactive, IL-17-producing T cells (17-19). The current study demonstrates that TGF- $\beta 1$ in the CNS may be critical in promoting disease. We propose that CNS-produced TGF- $\beta 1$ creates a permissive environment for the accumulation of pathogenic $\mathrm{T}$ cells and propagation of an autoimmune response. 


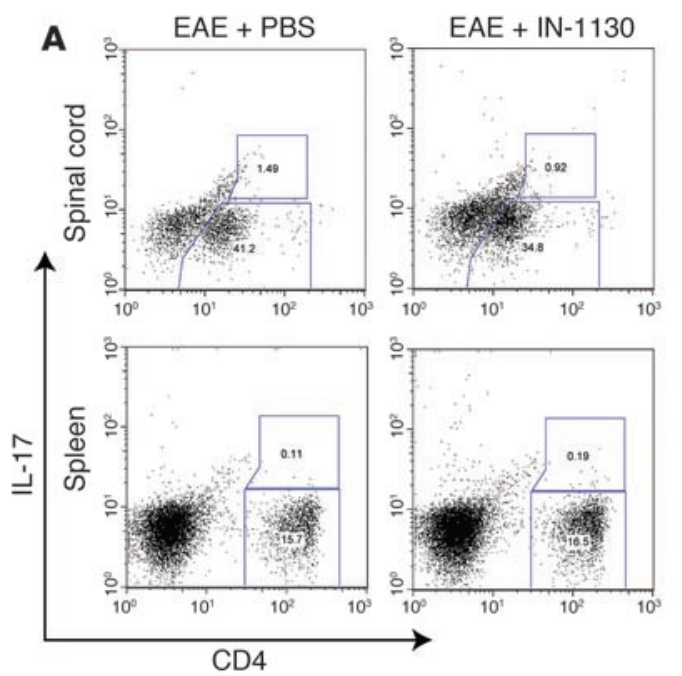

\section{Figure 6}

Inhibition of TGF- $\beta$ signaling by IN-1130 does not significantly affect the distribution of CD4 T cell subsets. C57BL/ 6 mice were immunized with $\mathrm{MOG}_{35-55}$ emulsified in CFA plus PT and treated with IN-1130 or PBS (i.p.) daily from 1-14 dpi. T cells were isolated from spinal cords and spleens of 6 mice combined at $20 \mathrm{dpi}$. Cells were stained with antibodies against CD4 in combination with IL-4, IFN- $\gamma$, Foxp3, and IL-17 and analyzed by flow cytometry. (A) Dot plots of IL-17 expression in CD4+ $\mathrm{T}$ cells from spinal cord (top panels) or spleen (bottom panels). (B and $\mathbf{C}$ ) Percentages of CD4 $\mathrm{T}$ cell subsets expressing the indicated intracellular markers from spinal cord (B) and spleen (C). No significant differences were observed in any of the percentages between IN-1130 (black bars) and PBS-treated (white bars) mice by FlowJo population comparison; $\mathrm{T}(\mathrm{X})=0$.
Our findings parallel observations in an experimental model of arthritis, where administering TGF- $\beta 1$ locally in the joint exacerbates the inflammatory response and aggravates disease (41), but systemic inoculation inhibits inflammation (42). Similarly, blocking endogenous TGF- $\beta 1$ by systemic injection of anti-TGF- $\beta 1$ neutralizing antibody exacerbates arthritis (43), but local blockage of TGF- $\beta 1$ ameliorates ongoing inflammation (44).

Pharmacological inhibition of TGF- $\beta$ signaling with the ALK5 kinase inhibitor IN-1130 resulted in delayed disease onset and overall less disease in $\mathrm{MOG}_{35-55}$-immunized mice (Figure 4 and Table 1). It was shown recently that transgenic mice with $\mathrm{CD} 4^{+} \mathrm{T}$ cells expressing a dominant-negative form of the TGF- $\beta$ type II receptor and thus, not responsive to TGF- $\beta 1$, failed to generate TH17 cells and did not develop EAE (20). Interestingly, inhibition of TGF- $\beta$ signaling with IN-1130 did not alter priming of $\mathrm{MOG}_{35-55^{-}}$ specific T cells nor their production of IL-17 or other cytokines involved in the generation of TH17 cells (Supplemental Figure 5). This suggests IN-1130 was not sufficient to interfere with TGF- $\beta$ signaling at the dendritic cell-T cell interface (20) and to block the generation of autoreactive TH17 cells in the periphery. IN-1130 also did not change the percentage of $\mathrm{CD}^{+} \mathrm{T}$ cell subsets in the CNS or the periphery (Figures 6 and 7). Nevertheless, IN-1130 treatment strongly inhibited GFAP- and SBE-dependent reporter gene transcription (Figure 4), reduced TGF- $\beta 1$ and IL- 6 mRNA levels in the CNS (Figure 5), reduced the percentage of $\mathrm{CD}^{+}$cells with activated TGF- $\beta$ signaling in spinal cord and spleen (Figure 7 ), and most importantly, potently suppressed the accumulation of T cells in the CNS (Figure 5 and Table 1). These results strongly indicate that the TGF- $\beta$-dependent effects observed after IN-1130 treatment go beyond the generation of TH17 cells and involve what we believe are novel immune-modulatory effects of TGF- $\beta 1$ in the CNS. This is also an example of the modulation of the immune system by the brain (23). Neurons have a crucial role in the regulation of the $\mathrm{T}$ cell response. Function of Tregs has recently been shown to be modulated by neuronal signals (22), and interestingly, IL-6 is a potent inhibitor of Treg differentiation (17). Finally, the modulation of weight loss (Figure 4 and Table 1) may indicate an interaction between the immune system and the hypothalamic pituitary axis, which is critical in leptin regulation (45). Leptin is both a fat modulator and a Th1 cytokine (proinflammatory).
Further emphasizing the importance of TGF- $\beta 1$ in the CNS during EAE, the overproduction of a constitutively active form of TGF- $\beta 1$ in astrocytes of transgenic mice resulted in an acceleration and exacerbation of disease after immunization with spinal cord homogenate (16) or $\mathrm{MOG}_{35-55}$ peptide (Supplemental Table 1). Again, T cell priming and production of cytokines after recall stimulation with $\mathrm{MOG}_{35-55}$ in culture were not affected by this tissue-restricted overexpression of TGF- $\beta 1$ (Supplemental Figure 3 ). In a related experiment, astrocyte-restricted overexpression of TGF- $\beta 1$ in a mouse model for Alzheimer disease resulted in increased $\mathrm{T}$ cell accumulation in the brain after immunization with the peptide that accumulates in the brains of these mice (46), indicating that the effect of TGF- $\beta 1$ on cerebral accumulation of $T$ cells is not restricted to myelin-specific cells. Because infiltrating $\mathrm{T}$ cells in EAE brains showed prominent activation of TGF- $\beta$ signaling (Figures 3 and 7 ), it is tempting to speculate that at least some of the disease-attenuating effect observed in mice with TGF- $\beta$ signaling-deficient $\mathrm{T}$ cells $(20)$ is related to their inability to respond to TGF- $\beta 1$ in the $\mathrm{CNS}$.

How TGF- $\beta 1$ regulates $T$ cell function and facilitates accumulation in the CNS requires further study. TGF- $\beta 1$ is strongly chemotactic for monocytes (47), neutrophils (48), and T cells (49) and induces the production of chemokines such as monocyte chemoattractant protein 1 (MCP-1) and several chemokine receptors (8). Besides this effect on chemotaxis, TGF- $\beta 1$ might increase homing to the brain by increasing adhesion molecules on infiltrating cells and the vasculature (8). Interestingly, unmanipulated GFAP-pTGF- $\beta 1$ mice, which produce significant amounts of bioactive TGF- $\beta 1$ in their brains, only slowly accumulate $T$ cells in the brain with aging (46). This suggests that, at least in the absence of autoimmune $\mathrm{T}$ cells, TGF- $\beta 1$ does not significantly increase chemotaxis or homing of T cells. Instead, TGF- $\beta 1$ may increase the survival of infiltrating $T$ cells via activation of antiapoptotic and prosurvival pathways (7). In the context of an immune reaction, such a function would obviously be ill-fated.

CFA is required to induce EAE, and we show that it is sufficient to activate TGF- $\beta 1$ production from glial cells and TGF- $\beta$ signaling in the CNS (Supplemental Figure 2). The effect of CFA is likely due to the presence of Mycobacterium tuberculosis, which strongly activates monocytes to produce TGF- $\beta 1$ in cell culture (50) and can also 

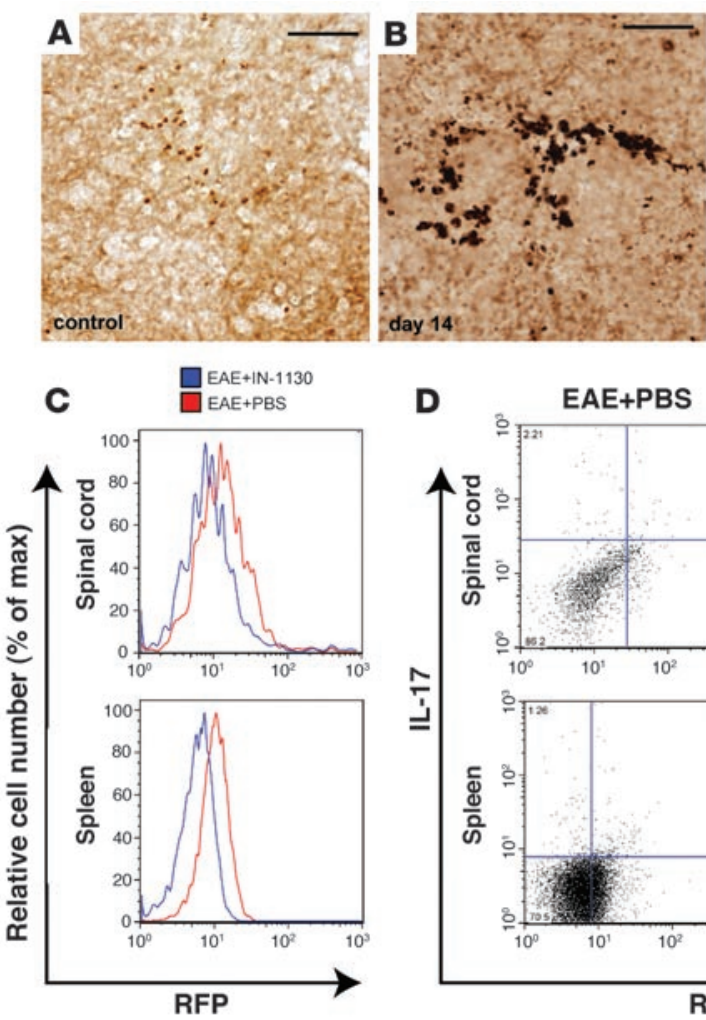

D
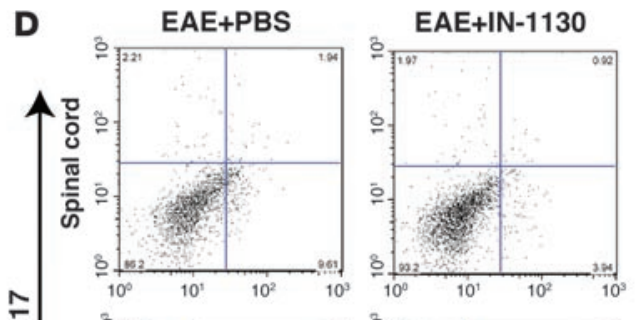

$\stackrel{\Upsilon}{=}$
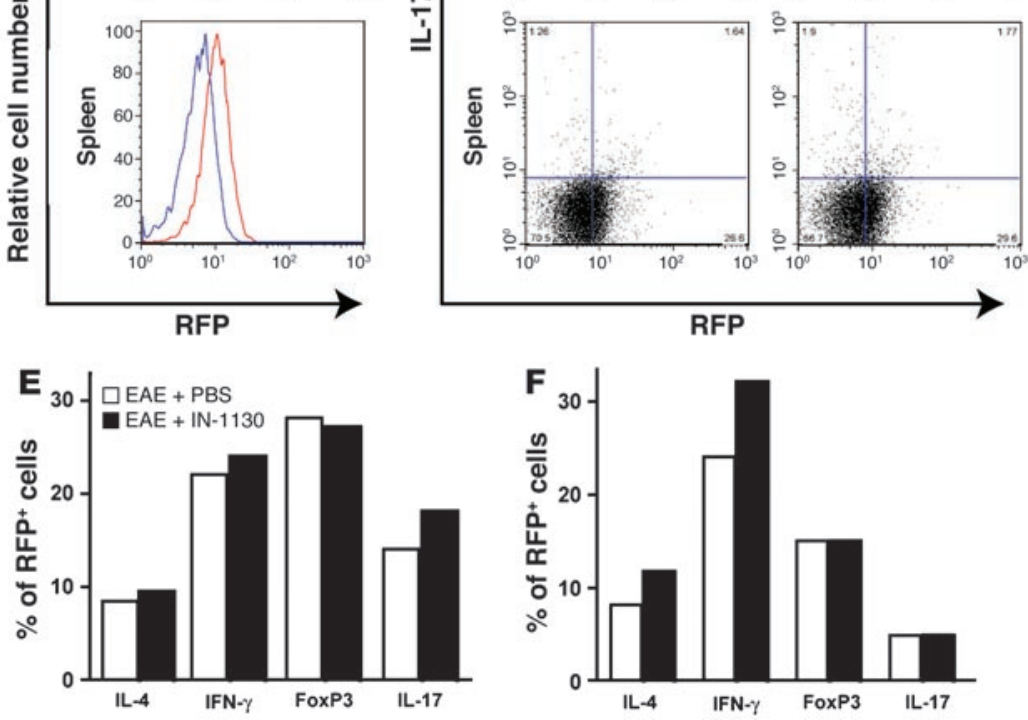

\section{Figure 7}

Treatment of IN-1130 inhibits TGF- $\beta$ signaling but does not significantly affect the distribution of CD4 T cell subsets with activated TGF- $\beta$ signaling. (A and B) Activation of TGF- $\beta$ signaling in lymphocytes from spleen sections of SBE-luRT mice with EAE (B) or no disease (A). Spleens were cut transversely at $40 \mu \mathrm{m}$ and the sections were stained for RFP (brain sections of the same mice are shown in Figure 3). (C-F) Flow cytometry analysis of $\mathrm{T}$ cells isolated from the spinal cord and spleen of IN-1130 or PBS-treated SBE-lucRT mice at $14 \mathrm{dpi}$ ( $n=5$ mice per group combined). Cells were stained with antibodies against RFP in combination with CD4, IL-4, IFN- $\gamma$, Foxp3, and IL-17. (C) IN-1130 significantly inhibits RFP expression in CD4 ${ }^{+} \mathrm{T}$ cells isolated from spinal cord (top panel) or spleen (bottom panel; FlowJo population comparison; $\mathrm{T}(\mathrm{X})=39.7$ for spinal cord, 1,240 for spleen). (D) Dot plots of all RFP+ cells expressing IL-17. (E and F) Percentages of RFP+ cells expressing the indicated intracellular markers in the spinal cord (E) and spleen (F). No significant differences were observed in any of the percentages between IN-1130 (black bars) and PBS-treated (white bars) mice by FlowJo population comparison; $\mathrm{T}(\mathrm{X})=0$.

signaling in the brain is activated by these innate immune triggers and may have a critical role in setting the conditions for local immune disease.

Our study investigates an important but often neglected aspect of autoimmune encephalomyelitis by exploring the conditions that facilitate the accumulation of autoimmune $\mathrm{T}$ cells in the CNS. We propose that TGF- $\beta 1$ has a key role in creating a permissive environment several days before the onset of clinical disease in EAE by activating TGF- $\beta$ signaling first in CNS cells and then in infiltrating T cells. The influence of TGF- $\beta$ signaling in glial cells of the nervous system on the immune system is striking here. Inhibition of TGF- $\beta$ signaling counteracts these events and therefore may have therapeutic benefits

convert latent TGF- $\beta 1$ to its bioactive form (51). Accordingly, these bacteria may be responsible for the observed increase in TGF- $\beta 1$ production in microglia and astrocytes in our model (Figure 2). M. tuberculosis can also stimulate IL-17 production in T cells (52) and induce TH17 cells in a TGF- $\beta 1$-dependent fashion (20). Given the observation that LPS is also a strong inducer of TGF- $\beta$ signaling in the CNS (31) and has been shown to promote relapses in EAE (53), it is tempting to speculate that bacterial infections may similarly promote relapses in MS patients (1) by creating a more permissive, proinflammatory environment in the CNS. Activation of glial cells by microbial signals is mediated primarily through pattern recognition receptors, of which TLRs are key participants (54-56). TLRs recognize microbial structural motifs referred to as pathogen-associated molecular patterns (PAMP). One TLR molecule, TLR4, binds LPS from Gram-negative bacteria. The engagement of the TLRs initiates TLR signaling cascade, leading to the activation of NF- $\mathrm{KB}$ (57), which in turn induces the transcription of proinflammatory cytokines, chemokines, and upregulation of cell surface molecules. The critical role of the canonical pathway of $\mathrm{NF}-\kappa \mathrm{B}$ in EAE was shown when this pathway of NF- $\mathrm{KB}$ signaling was targeted in astrocytes $(24,58)$. Our studies show that TGF- $\beta$ in the early phases of autoimmune inflammation in the CNS.

\section{Methods}

Mice. The following transgenic mouse lines were used: C57BL/6 (The Jackson Laboratory), SBE-luc (line T9-7BA on the C57BL/6J-Tyr-2J genetic background, "responder" mice screened by detectable luciferase activity in tail biopsies were used in bioluminescence imaging experiments) (31, 32), GFAP-pTGF- $\beta 1$ (line T64B on the C57BL/ 6 genetic background, contain a constitutively active mutant of porcine TGF- $\beta 1$ under control of a GFAP promoter) (36), SBE-lucRT (line T182-103 express a fusion protein containing luciferase, $\underline{R} F$, and thymidine kinase (33) under the control of SBE promoter), and GFAP-luc (26). SBE-lucRT and GFAP-luc mice, originally generated on the FVB/N genetic background, were crossed with C57BL/6J-Tyr ${ }^{\mathrm{c}-2 \mathrm{~J}}$ mice, and F1 offspring were used for experiments. Mice were between 8 and 12 weeks of age when experiments were initiated. All animal care and use was in accordance with institutional guidelines and approved by the VA Palo Alto Committee on Animal Research.

EAE induction, assessment, and IN-1130 treatment. $\mathrm{MOG}_{35-55}$ peptide (MEVGWYRSPFSRVVHLYRNGK) was synthesized by the Stanford Protein and Nucleic Acid Biotechnology Facility and purified by high-performance liquid chromatography to greater than $95 \%$ purity. Mice were immunized 
s.c. with $200 \mu \mathrm{g}$ of $\mathrm{MOG}_{35-55}$ peptide emulsified in CFA and received an i.v. injection of $400 \mathrm{ng}$ of PT (List Biological Laboratories Inc.) at the time of immunization and 48 hours later. Mice were examined daily for clinical signs of EAE and scored as follows: 0 , no paralysis; 1 , loss of tail tone; 2, hind limb weakness; 3 , hind limb paralysis; 4 , hind limb and forelimb paralysis; 5, moribund or dead. For IN-1130 treatment, IN-1130 was freshly prepared in PBS every day as described previously (37). Animals were treated i.p. once daily with either vehicle (PBS) or IN-1130 (30 mg/kg), starting at 1 or $3 \mathrm{dpi}$ and up to $14 \mathrm{dpi}$.

Bioluminescence imaging. Bioluminescence was detected with the In Vivo Imaging System (IVIS; Xenogen Corporation) (31, 32), which utilizes a cooled charged coupled device (CCD) camera. Mice were injected i.p. with $150 \mathrm{mg} / \mathrm{kg}$ D-luciferin (Xenogen Corp.) 10 minutes before imaging and anesthetized with isoflurane during imaging. Imaging signal was quantitated as photons $/ \mathrm{s} / \mathrm{cm}^{2} /$ steridian ( $\mathrm{sr}$ ) using LIVINGIMAGE software (version 2.50) (Xenogen Corporation) and integrated over 5 minutes for SBE-luc mice or 3 minutes for GFAP-luc mice. For signal quantification, photons were obtained from a region of interest which was kept constant in area and positioning within all experiments. For longitudinal comparison of bioluminescence, baseline imaging was performed 24 hours before EAE was initiated. Bioluminescence was expressed as fold induction over baseline levels. In addition, a background bioluminescence reading obtained in nontransgenic mice injected with D-luciferin was subtracted from all values.

Tissue preparations. Mice were anesthetized with $400 \mathrm{mg} / \mathrm{kg}$ chloral hydrate (Sigma-Aldrich) and transcardially perfused with $0.9 \%$ saline. Brains and spinal cords were removed. Brains were dissected into 2 hemibrains and spinal cords into 4 equal segments. One hemibrain and 2 spinal cord segments were fixed for 24 hours in $4 \%$ paraformaldehyde and cryoprotected in $30 \%$ sucrose. Brains were sectioned sagittally, and spinal cords were cut transversely at $40 \mu \mathrm{m}$ using a freezing microtome (Leica Camera Inc.) and stored in cryoprotective medium. The other hemibrain and 2 other spinal cord segments were snap-frozen and stored at $-80^{\circ} \mathrm{C}$ for tissue luciferase measurements or qPCR. For luciferase activity measurements, brain tissue was weighed and lysed in 100-400 $\mu \mathrm{l}$ of $1 \times$ Cell Culture Lysis Reagent (Promega). Luciferase activities from tissue homogenates were measured using a luciferase assay kit (Promega) with a plate luminometer (Molecular Devices Corporation) and normalized to weight.

Immunohistochemistry. Immunohistochemistry was performed on freefloating sections following standard procedures (32). Primary antibodies were against TGF- $\beta 1$ (1:100; R\&D Systems), RFP (1:200; Chemicon), GFAP (1:1,000; Dako), CD68 (1:50; Serotec), CD3 (1:1,000; BD Biosciences), and CD4 (1:100; BD Biosciences). Primary antibody staining was revealed using biotinylated secondary antibodies and the ABC kit (Vector) with diaminobenzidine (DAB; Sigma-Aldrich). For double immunolabeling, the TGF- $\beta 1$ or RFP signal was amplified by a tyramide signal amplification (TSA) kit (Invitrogen). T cells (CD3 ${ }^{+}$cells) were counted in 2-4 spinal cord coronal sections per mouse. Quantification of the percentage of area covered by TGF- $\beta 1$ immunostaining was performed by Metamorph software (Molecular Devices Corporation) (32).

$T$ cell proliferation assays. Splenocytes were isolated and cultured in vitro in enriched RPMI 1640 alone as a negative control or with the specific encephalitogenic peptide. Cells were cultured in 96-well plates at a concentration of $5 \times 10^{6}$ cells $/ \mathrm{ml}$ for 96 hours. Cultures were pulsed for the final 16 hours with $1 \mu \mathrm{Ci}$ per well of ${ }^{3} \mathrm{H}$ thymidine (Amersham Pharmacia Biotech) before incorporated radioactivity was measured using a $\beta$ plate scintillation counter.

Cytokine analysis. Supernatants from splenocytes cultured in parallel with those cells used in proliferation assays were used for cytokine analysis. Supernatants were collected for measurements of cytokine levels of IL-6, IL-12, IL-17, and IL-23. Cytokine levels were determined using spe- cific ELISA kits for the corresponding cytokines according to the manufacturers' protocols (eBioscience and BD Biosciences).

Quantitative real-time PCR. Total RNA was isolated from spinal cords using Absolutely RNA Miniprep Kit (Stratagene) and converted to cDNA using SuperScript II RNase H- Reverse Transcriptase (Invitrogen) for first-strand cDNA synthesis. The cDNA product was used for real-time quantitative PCR using a high-speed thermal cycler (LightCycler3; Roche Diagnostics) and detection of product by SYBR green I (QIAGEN). PCR primers were as follows: for detection of TGF- $\beta 1$, forward 5 -CGTGGAAATCAACGGG-3', reverse 5'-CAGAAGTTGGCATGGT-3'; for detection of IL-6, forward 5'ACAACCACGGCCTTCCCTAC-3', reverse 5'-TCCACGATTTCCCAGAGAACA-3'; and for detection of IL-23, forward 5'-AATGTGCCCCGTATCC-3', reverse 5'-GGAGGTGTGAAGTTGCT-3' (Operon Biotechnologies Inc.). Melting curves confirmed that only 1 product was amplified. Specific cDNA was quantified with a standard curve based on known amounts of amplified $\beta$-actin fragment and expressed as fold increase over baseline levels obtained from nonimmunized control mice.

Isolation of T cells from CNS tissue. Brains and spinal cords were obtained from mice with EAE after PBS perfusion and were ground through a cell strainer and digested with $300 \mathrm{U} / \mathrm{ml}$ clostridial collagenase (type V) to obtain a single-cell suspension. CNS-derived cells were washed and resuspended in $30 \%$ Percoll, underlayed with 70\% Percoll, and centrifuged at $500 \mathrm{~g}$ for 20 minutes. CNS mononuclear cells were collected from the $30 \% / 70 \%$ interface.

Flow cytometric analysis. Cells obtained from spinal cords or spleens were washed and incubated with anti-CD16/32 to occupy Fc receptors and prevent nonspecific staining. All cells were first stained with anti-CD4-FITC. They were then fixed and permeabilized with Cytofix/Cytoperm (BD Biosciences) and incubated with PE-conjugated antibodies against IL-4, IFN- $\gamma$, Foxp3, and IL-17 (BD Biosciences) for intracellular staining. To determine the expression of RFP, cells isolated from SBE-lucRT mice were stained with anti-RFP-FITC (Abcam Inc.) and PE-conjugated antibodies. Stained cells were analyzed with a BD FACScan flow cytometer, and data were analyzed with FlowJo 8.5.2 (Tree Star Inc.).

Statistics. Data were expressed as mean \pm SEM. Statistical analyses were performed with Prism 4.03 software (GraphPad Software). Means between 2 groups were compared with 2 -tailed, unpaired Student's $t$ test; comparisons of means from multiple groups with 1 control were analyzed with 1 -way ANOVA and Dunnett's or Tukey's post hoc test. Comparing distributions of FACS data was performed with FlowJo Population Comparison Algorithm. A value $T(X)$ was obtained and was used to estimate the probability that a test population was different from a control population. When $\mathrm{T}(\mathrm{X})=0,2$ histograms are indistinguishable $(P=0.5) ; \mathrm{T}(\mathrm{X})>4$ indicates that 2 distributions are different with $P<0.01$ (99\% confidence).

\section{Acknowledgments}

We thank Xenogen (now a part of Caliper Life Sciences) for providing the GFAP-luc mice; $\mathrm{M}$. Britschgi for technical assistance in dissecting spinal cords; and B. Debsi, W. Wang, and H. Yang for animal husbandry and genotyping. This work was supported by grants from the NIH (AG23708, AG20603) and the John Douglas French Alzheimer's Foundation (to T. Wyss-Coray) and from the NCI (CA114747 ICMIC P5; to S.S. Gambhir).

Received for publication February 9, 2007, and accepted in revised form August 15, 2007.

Address correspondence to: T. Wyss-Coray, Department of Neurology and Neurological Sciences, Stanford University, SUMC Room A343, Stanford, California 94305-5235, USA. Phone: (650) 8523220; Fax: (650) 849-0434; E-mail: twc@stanford.edu. 
1. Steinman, L. 1996. Multiple sclerosis: a coordinated immunological attack against myelin in the central nervous system. Cell. 85:299-302.

2. Steinman, L. 2001. Multiple sclerosis: a two-stage disease. Nat. Immunol. 2:762-764.

3. Gold, R., Linington, C., and Lassmann, H. 2006. Understanding pathogenesis and therapy of multiple sclerosis via animal models: 70 years of merits and culprits in experimental autoimmune encephalomyelitis research. Brain. 129:1953-1971.

4. Steinman, L. 1999. Assessment of animal models for MS and demyelinating disease in the design of rational therapy. Neuron. 24:511-514.

5. Massagué, J., Blain, S.W., and Lo, R.S. 2000. TGF- $\beta$ signaling in growth control, cancer, and heritable disorders. Cell. 103:295-309.

6. Dennler, S., Goumans, M.-J., and ten Dijke, P. 2002. Transforming growth factor $\beta$ signal transduction. J. Leukoc. Biol. 71:731-740.

7. Li, M.O., Wan, Y.Y., Sanjabi, S., Robertson, A.K., and Flavell, R.A. 2006. Transforming growth factor-beta regulation of immune responses. Annu. Rev. Immunol. 24:99-146.

8. Luethviksson, B.R., and Gunnlaugsdottir, B. 2003. Transforming growth factor-beta as a regulator of site-specific T-cell inflammatory response. Scand. J. Immunol. 58:129-138.

9. Schmid, P., Cox, D., Bilbe, G., Maier, R., and McMaster, G.K. 1991. Differential expression of TGF beta 1, beta 2 and beta 3 genes during mouse embryogenesis. Development. 111:117-130.

10. Mattson, M.P., et al. 1997. Cellular signaling roles of TGF $\beta$, TNF $\alpha$ and $\beta$ APP in brain injury responses and Alzheimer's disease. Brain Res. Rev. 23:47-61.

11. De Groot, C.J., Montagne, L., Barten, A.D., Sminia, P., and Van Der Valk, P. 1999. Expression of transforming growth factor (TGF)-beta1, -beta2, and -beta3 isoforms and TGF-beta type I and type II receptors in multiple sclerosis lesions and human adult astrocyte cultures. J. Neuropathol. Exp. Neurol. 58:174-187.

12. Issazadeh, S., et al. 1995. Interferon gamma, interleukin 4 and transforming growth factor beta in experimental autoimmune encephalomyelitis in Lewis rats: dynamics of cellular mRNA expression in the central nervous system and lymphoid cells. J. Neurosci. Res. 40:579-590.

13. Johns, L.D., Flanders, K.C., Ranges, G.E., and Sriram, S. 1991. Successful treatment of experimental allergic encephalomyelitis with transforming growth factor. J. Immunol. 147:1792.

14. Kuruvilla, A.P., et al. 1991. Protective effect of transforming growth factor beta 1 on experimental autoimmune diseases in mice. Proc. Natl. Acad. Sci. U. S. A. 88:2918-2921.

15. Johns, L.D., and Sriram, S. 1993. Experimental allergic encephalomyelitis: neutralizing antibody to TGF beta 1 enhances the clinical severity of the disease. J. Neuroimmunol. 47:1-7.

16. Wyss-Coray, T., Borrow, P., Brooker, M.J., and Mucke, L. 1997. Astroglial overproduction of TGF- $\beta 1$ enhances inflammatory central nervous system disease in transgenic mice. J. Neuroimmunol. 77:45-50.

17. Bettelli, E., et al. 2006. Reciprocal developmental pathways for the generation of pathogenic effector TH17 and regulatory T cells. Nature. 441:235-238.

18. Mangan, P.R., et al. 2006. Transforming growth factor-beta induces development of the $\mathrm{T}(\mathrm{H}) 17$ lineage. Nature. 441:231-234

19. Veldhoen, M., Hocking, R.J., Atkins, C.J., Locksley, R.M., and Stockinger, B. 2006. TGFbeta in the context of an inflammatory cytokine milieu supports de novo differentiation of IL-17-producing T cells. Immunity. 24:179-189.

20. Veldhoen, M., Hocking, R.J., Flavell, R.A., and Stockinger, B. 2006. Signals mediated by transforming growth factor-beta initiate autoimmune encepha- lomyelitis, but chronic inflammation is needed to sustain disease. Nat. Immunol. 7:1151-1156.

21. Steinman, L. 2007. A brief history of $\mathrm{T}(\mathrm{H}) 17$, the first major revision in the $\mathrm{T}(\mathrm{H}) 1 / \mathrm{T}(\mathrm{H}) 2$ hypothesis of $\mathrm{T}$ cell-mediated tissue damage. Nat. Med. 13:139-145.

22. Liu, Y., Teige, I., Birnir, B., and Issazadeh-Navikas, S. 2006. Neuron-mediated generation of regulatory $\mathrm{T}$ cells from encephalitogenic $\mathrm{T}$ cells suppresses EAE. Nat. Med. 12:518-525.

23. Steinman, L. 2004. Elaborate interactions between the immune and nervous systems. Nat. Immunol. 5:575-581.

24. van Loo, G., et al. 2006. Inhibition of transcription factor NF-kappaB in the central nervous system ameliorates autoimmune encephalomyelitis in mice. Nat. Immunol. 7:954-961.

25. Fujinami, R.S. 2006. Neurons tame T cells. Nat. Med. 12:503-504

26. Zhu, L., et al. 2004. Non-invasive imaging of GFAP expression after neuronal damage in mice. Neurosci. Lett. 367:210-212.

27. Aquino, D.A., Shafit-Zagardo, B., Brosnan, C.F., and Norton, W.T. 1990. Expression of glial fibrillary acidic protein and neurofilament mRNA in gliosis induced by experimental autoimmune encephalomyelitis. J. Neurochem. 54:1398-1404.

28. Tani, M., et al. 1996. In situ hybridization analysis of glial fibrillary acidic protein mRNA reveals evidence of biphasic astrocyte activation during acute experimental autoimmune encephalomyelitis. Am. J. Pathol. 148:889-896.

29. Lindholm, D., Castren, E., Kiefer, R., Zafra, F., and Thoenen, H. 1992. Transforming growth factor- $\beta 1$ in the rat brain: increase after injury and inhibition of astrocyte proliferation. J. Cell Biol. 117:395-400.

30. Knuckey, N.W., et al. 1996. Differential neuronal and astrocytic expression of transforming growth factor beta isoforms in rat hippocampus following transient forebrain ischemia. Mol. Brain Res. 40:1-14.

31. Lin, A.H., et al. 2005. Global analysis of Smad2/3dependent TGF- $\{$ beta $\}$ signaling in living mice reveals prominent tissue-specific responses to injury. J. Immunol. 175:547-554.

32. Luo, J., Lin, A.H., Masliah, E., and Wyss-Coray, T. 2006. Bioluminescence imaging of Smad signaling in living mice shows correlation with excitotoxic neurodegeneration. Proc. Natl. Acad. Sci. U. S. A. 103:18326-18331.

33. Ray, P., De, A., Min, J.J., Tsien, R.Y., and Gambhir, S.S. 2004. Imaging tri-fusion multimodality reporter gene expression in living subjects. Cancer Res. 64:1323-1330.

34. Linthicum, D.S., Munoz, J.J., and Blaskett, A. 1982. Acute experimental autoimmune encephalomyelitis in mice. I. Adjuvant action of Bordetella pertussis is due to vasoactive amine sensitization and increased vascular permeability of the central nervous system. Cell. Immunol. 73:299-310.

35. Svet-Moldavsky, G.J., Svet-Moldavskaya, I.A., and Raffkina, L.I. 1959. Various types of acquired resistance to experimental 'allergic' encephalomyelitis. Nature. 184:1552-1553.

36. Wyss-Coray, T., Lin, C., Sanan, D., Mucke, L., and Masliah, E. 2000. Chronic overproduction of TGF- $\beta 1$ in astrocytes promotes Alzheimer's disease-like microvascular degeneration in transgenic mice. Am. J. Pathol. 156:139-150.

37. Moon, J.A., Kim, H.T., Cho, I.S., Sheen, Y.Y., and Kim, D.K. 2006. IN-1130, a novel transforming growth factor-beta type I receptor kinase (ALK5) inhibitor, suppresses renal fibrosis in obstructive nephropathy. Kidney Int. 70:1234-1243.

38. Van Obberghen-Schilling, E., Roche, N.S., Flanders, K.C., Sporn, M.B., and Roberts, A.B. 1988. Transforming growth factor beta 1 positively regulates its own expression in normal and transformed cells. J. Biol. Chem. 263:7741-7746.
39. Jones, S.A. 2005. Directing transition from innate to acquired immunity: defining a role for IL-6. J. Immunol. 175:3463-3468.

40. Tato, C.M., and O'Shea, J.J. 2006. Immunology: what does it mean to be just 17? Nature. 441:166-168.

41. Allen, J.B., et al. 1990. Rapid onset synovial inflammation and hyperplasia induced by transforming growth factor beta. J. Exp. Med. 171:231-247.

42. Brandes, M.E., Allen, J.B., Ogawa, Y., and Wahl, S.M. 1991. Transforming growth factor $\beta 1$ suppresses acute and chronic arthritis in experimental animals. J. Clin. Invest. 87:1108-1113.

43. Thorbecke, G.J., et al. 1992. Involvement of endogenous tumor necrosis factor alpha and transforming growth factor beta during induction of collagen type II arthritis in mice. Proc. Natl. Acad. Sci. U. S. A. 89:7375-7379.

44. Wahl, S.M., Allen, J.B., Costa, G.L., Wong, H.L., and Dasch, J.R. 1993. Reversal of acute and chronic synovial inflammation by anti-transforming growth factor beta. J. Exp. Med. 177:225-230.

45. Steinman, L., Conlon, P., Maki, R., and Foster, A. 2003. The intricate interplay among body weight, stress, and the immune response to friend or foe. J. Clin. Invest. 111:183-185. doi:10.1172/ JCI200317622.

46. Buckwalter, M.S., et al. 2006. Increased T cell recruitment to the CNS after amyloid beta 1-42 immunization in Alzheimer's mice overproducing transforming growth factor-beta 1. J. Neurosci. 26:11437-11441.

47. Wahl, S.M., et al. 1987. Transforming growth factor type beta induces monocyte chemotaxis and growth factor production. Proc. Natl. Acad. Sci. U. S. A. 84:5788-5792.

48. Reibman, J., et al. 1991. Transforming growth factor beta 1 , a potent chemoattractant for human neutrophils, bypasses classic signal-transduction pathways. Proc. Natl. Acad. Sci. U. S. A. 88:6805-6809.

49. Adams, D.H., et al. 1991. Transforming growth factor-beta induces human $\mathrm{T}$ lymphocyte migration in vitro. J. Immunol. 147:609-612.

50. Toossi, Z., et al. 1995. Induction of transforming growth factor beta 1 by purified protein derivative of Mycobacterium tuberculosis. Infect. Immun. 63:224-228.

51. Aung, H., Wu, M., Johnson, J.L., Hirsch, C.S., and Toossi, Z. 2005. Bioactivation of latent transforming growth factor beta1 by Mycobacterium tuberculosis in human mononuclear phagocytes. Scand. J. Immunol. 61:558-565.

52. Infante-Duarte, C., Horton, H.F., Byrne, M.C., and Kamradt, T. 2000. Microbial lipopeptides induce the production of IL-17 in Th cells. J. Immunol. 165:6107-6115.

53. Nogai, A., et al. 2005. Lipopolysaccharide injection induces relapses of experimental autoimmune encephalomyelitis in nontransgenic mice via bystander activation of autoreactive CD4+ cells. J. Immunol. 175:959-966.

54. Jack, C.S., et al. 2005. TLR signaling tailors innate immune responses in human microglia and astrocytes. J. Immunol. 175:4320-4330.

55. McKimmie, C.S., and Fazakerley, J.K. 2005. In response to pathogens, glial cells dynamically and differentially regulate Toll-like receptor gene expression. J. Neuroimmunol. 169:116-125.

56. Olson, J.K., and Miller, S.D. 2004. Microglia initiate central nervous system innate and adaptive immune responses through multiple TLRs. J. Immunol. 173:3916-3924.

57. Moynagh, P.N. 2005. TLR signalling and activation of IRFs: revisiting old friends from the NF-kappaB pathway. Trends Immunol. 26:469-476.

58. Youssef, S., and Steinman, L. 2006. At once harmful and beneficial: the dual properties of NF-kappaB. Nat. Immunol. 7:901-902. 